Published in final edited form as:

Br J Dermatol. 2018 February ; 178(2): 350-356. doi:10.1111/bjd.15896.

\title{
Colchicine: an ancient drug with novel applications
}

\author{
B. Dasgeb ${ }^{2,3}$, D. Kornreich ${ }^{2}$, K. McGuinn' ${ }^{2}$, L. Okon², I. Brownell ${ }^{4}$, and D. L. Sackett ${ }^{1}$ \\ ${ }^{1}$ Division of Basic and Translational Biophysics, Eunice Kennedy Shriver National Institute of Child \\ Health and Human Development, $\mathrm{NIH}$, Bethesda, MD \\ 2Department of Dermatology and Cutaneous Biology, Thomas Jefferson University, Philadelphia, \\ Pennsylvania, USA \\ ${ }^{3}$ Section of Analytical and Functional Biophotonics, Eunice Kennedy Shriver National Institute of \\ Child Health and Human Development, NIH, Bethesda, MD \\ ${ }^{4}$ Dermatology Branch, Center for Cancer Research, National Cancer Institute, NIH, Bethesda, \\ $\mathrm{MD}$
}

\begin{abstract}
Colchicine is a historic treatment for gout that has been used for more than a millennium. It is the treatment of choice for Familial Mediterranean Fever and its associated complication, amyloidosis. The 2009 FDA approval of colchicine as a new drug had research consequences. Recent investigations utilizing large cohorts of gout patients who have been taking colchicine for years have demonstrated novel applications within oncology, immunology, cardiology and dermatology. Some emerging dermatologic uses include the treatment of epidermolysis bullosa acquisita, leukocytoclastic vasculitis, aphthous stomatitis and others. In this work we relate the history and the new horizon of this ancient medicine.
\end{abstract}

\section{History}

Colchicine is one of the oldest remedies still in use today. It is derived from the bulb-like corms of the Colchicum autumnale plant, also known as autumn crocus. Its history as an herbal remedy for joint pain goes back at least to the 1500 BCE Egyptian manuscript, the Ebers Papyrus (Figure 1). The active ingredient, colchicine (Figure 2), was isolated in the early 1800 's and remains in use today as a purified natural product. ${ }^{1}$ In view of the long history of colchicine's use in medicine, it is perhaps surprising that it was not until 2009 that colchicine was approved by the U.S. Federal Drug Administration. ${ }^{2}$

Corresponding Authors: Dan Sackett, PhD, sackettd@mail.nih.gov, Phone: 301-594-0358, 9 MEMORIAL DR Room 1E129, MSC 0924 Bethesda MD 20892-0924. Bahar Dasgeb, MD. bahardasgeb@gmail.com. Phone: 301-435-9235. 49 CONVENT DR Room 5A82, MSC 4480. Bethesda MD 20892-4480.

DR BAHAR DASGEB (Orcid ID : 0000-0002-8185-1821)

There are no conflicts of interest to disclose. 


\section{Mechanism of Action}

Despite its use for thousands of years, colchicine's exact mechanism of action is still being explored. In the 1950's and 1960's the microtubule (MT) was identified as the primary cellular target. MTs serve as a major part of our cellular cytoskeleton, and are essential to cellular functions such as mitosis, as well as intracellular organelle and vesicle trafficking. ${ }^{3,4}$ MT dynamics originate in a balance of polymer growth and shrinkage, mostly at the MT end that is distal to the nucleus. These dynamics allow changes in MT distribution and in overall cell shape (Figure 3). Structurally, MT are hollow cylinders composed of protofilaments, which in turn are made from a $\beta$-tubulin heterodimers polymerized end to end. Colchicine binds to tubulin heterodimers and alters the tubulin conformation, allowing the tubulin dimer-colchicine complex to add to the growing end of a MT but preventing any further growth, thus poisoning the dynamics of that MT. The exact mechanism by which this colchicine induced MT destabilization leads to alteration of cell function remains unclear.

Colchicine impairs neutrophil function by impacting inflammatory pathways and mediators of neutrophil activation. The drug decreases neutrophil L-selectin expression and modulates E-selectin expression on the cell surface of endothelial cells, thereby impairing neutrophil recruitment. ${ }^{5}$ It further prevents neutrophil migration by decreasing the inducing effects of platelet activating factor and leukotriene- $\beta 4$ on neutrophil adherence. ${ }^{6}$ Neutrophil function is additionally compromised by colchicine via suppression of neutrophil superoxide production, a key contributor to the inflammatory response seen in neutrophil activation. ${ }^{7}$

By impairing vesicular trafficking, colchicine is able to both decrease TNF- $a$ receptor expression on macrophages (preventing activation) and interrupt granule release in mast cells (preventing degranulation). ${ }^{4}$ In keeping with this effect on inflammatory modulators, in vivo and in vitro studies demonstrate decreased levels of the proinflammatory cytokines IL-1 $\beta$, IFN $\gamma$, IL-18 and IL- 6 with colchicine use. ${ }^{8}$ Given these extensive effects on inflammation, it is not surprising that the use of colchicine has been explored in a number of inflammatory conditions.

\section{Traditional Indications: the Old}

\section{Gout and Pseudogout}

Colchicine has been known as a treatment for gout for several millenia. Inflammation in gout is mediated by a combination of neutrophil and macrophage activation, leukocyte adhesion molecules, inflammasome activation as well as IL-1 $\beta$ production. As noted above, all of these pathways are affected by colchicine. ${ }^{2}$ Despite its longstanding use, few randomized controlled trials have evaluated its efficacy empirically. In the first randomized, placebo-controlled trial assessing the efficacy and toxicity of colchicine in acute gout, patients were treated with an initial $1 \mathrm{mg}$ dose followed by sequential doses of $0.5 \mathrm{mg}$ every 2 hours until either significant symptomatic relief or intolerance. The authors found that two-thirds of colchicine-treated patients experienced pain reduction within 48 hours, compared with one-third of patients in the placebo group experiencing similar response; however, patients reported diarrhea prior to relief of symptoms. ${ }^{9}$ 
The AGREE (Acute Gout Flare Receiving Colchicine Evaluation) trial was the first randomized, placebo-controlled trial to compare low and high-dose colchicine. In this study, 184 patients experiencing acute gout flares were randomized to either a low dose regimen ( $1.2 \mathrm{mg}$ dose followed by one $0.6 \mathrm{mg}$ dose one hour later), a high-dose regimen (1.2 $\mathrm{mg}$ dose followed by one $0.6 \mathrm{mg}$ dose every hour up to a maximum of $4.8 \mathrm{mg}$ ), or placebo. The authors found a comparable response rate in the low-dose group versus the high-dose group with both found to be superior to placebo. Importantly, they also noted that the high-dose was associated with more diarrhea and vomiting. ${ }^{10}$

In addition to the use of colchicine in acute flares, evidence supports its use as a prophylactic agent in certain patients with chronic gout. A placebo-controlled randomized trial evaluating colchicine for flare prophylaxis in patients initiating allopurinol found that subjects treated with colchicine had fewer and less severe flares. ${ }^{11}$ An analysis of three randomized controlled trials evaluating 4101 patients initiating urate-lowering therapy with either febuxostat or allopurinol found that prophlyactic colchicine taken for up to 6 months provided greater reduction in flare rates as compared to an 8 week course. ${ }^{12}$

Colchicine is also recommended for the treatment of acute flares, as well as flare prophylaxis, in patients with pseudogout or calcium pyrophosphate crystal arthritis. According to current European League Against Rheumatism (EULAR) guidelines, $0.5 \mathrm{mg}$ of colchicine should be prescribed for pseudogout prophylaxis, and $0.5 \mathrm{mg}$ three times daily, with or without a $1 \mathrm{mg}$ loading dose, should be administered for acute attacks. ${ }^{13}$

\section{Familial Mediterranean Fever}

Familial Mediterranean Fever (FMF) is characterized by recurrent attacks of fever, arthritis and serositis. This condition is caused by a mutation in the gene that encodes pyrin, a protein that regulates inflammasome activation. This mutation permits exuberant IL-1 $\beta$ production and inflammatory attacks. ${ }^{2}$

Colchicine has been the treatment of choice for Familial Mediterranean Fever (FMF) since the 1970's. Two seminal randomized controlled trials in 1974 found that patients treated with colchicine for one to two months experienced significantly fewer attacks. ${ }^{14}$ Several long term follow-up studies, including one longitudinal study in which 45 affected patients taking colchicine for a minimum of 15 years, provided favorable support for the safety and efficacy of this therapy. ${ }^{15}$

Amyloid A amyloidosis, which occurs in up to $90 \%$ of untreated FMF patients, leads to chronic renal failure, typically within 5 years after the onset of proteinuria. Colchicine is considered to be the prophylactic treatment of choice for secondary amyloidosis. ${ }^{16}$ Colchicine, in daily doses of 1 to $2 \mathrm{mg}$, not only prevents or significantly reduces the frequency of FMF attacks in 90 to $95 \%$ of patients, but it almost universally prevents the development of amyloidosis. ${ }^{2}$ It has been shown to prevent development of proteinuria, which is the underlying etiology of renal failure due to amyloidosis in patients with FMF. ${ }^{17}$ Even in patients with established amyloid nephropathy, colchicine has been shown to induce remission of proteinuria and nephrotic syndrome. Additionally, a randomized cohort study showed favorable efficacy of colchicine in treatment of secondary amyloidosis. The same 
trial showed increased survival in a patient who received colchicine compared to the cohort who received combination of melphalan and prednisone. ${ }^{18}$ It is important to emphasize that use of colchicine is proven safe in children, as well as in pregnant and nursing women. ${ }^{19}$

\section{Potential Indications: the New}

The potential uses of colchicine have broadened significantly over the last few years as new studies have emerged demonstrating novel applications within oncology, immunology, cardiology, and dermatology. Many of these studies utilize the large cohort of gout patients who have been taking colchicine for years to decades in order to assess significant trends and associations as follows:

\section{Uses in Dermatology}

Colchicine has been reported to be an efficacious and well-tolerated treatment for numerous dermatologic diseases; however, the data is mostly limited to small case reports and series. Behçet's disease, epidermolysis bullosa acquisita, leukocytocastic vasculitis, Sweet's syndrome and recurrent apthous stomatitis are some of the few dermatologic diseases in which treatment with colchicine has been studied more extensively, as seen in Table 1.

\section{Behçet's Syndrome}

Behçet's syndrome is a systemic vasculitis characterized clinically by recurrent oral and genital ulceration, arthritis, uveitis, as well as variable cutaneous, gastrointestinal, and neurologic involvement. Studies have supported the efficacy of colchicine in the treatment of the mucosal, cutaneous, pleuropericardial and abdominal complications of this disease.

Colchicine is hypothesized to exert its effect in Behçet's syndrome through leukocyte chemotaxis. In 1975, Matsumara and Mizushima first published improvement of Behçet's disease with colchicine therapy; specifically, 7 of 12 patients had moderate improvement in symptoms following treatment with colchicine $0.5 \mathrm{mg}$ twice a day. ${ }^{20}$ Decades later, a double-blind controlled trial in which 116 patients with Behçet's syndrome were randomized to receive either colchicine or placebo for two years showed significant reductions in the occurrence of genital ulcers, erythema nodosum, and arthritis in female patients, as well as a reduction in the incidence of arthritic symptoms in men. ${ }^{3,21}$ Davitchi et al performed a crossover trial of 169 patients who fulfilled Behçet's criteria, in which patients were randomly assigned to receive colchicine or placebo for four months, and then swapped over (colchicine to placebo, placebo to colchicine) for an additional four months. The authors of this study found significant improvements in IBDDAM (Iranian Behçet's Disease Dynamic Activity Measure), a validated outcome measure, as opposed to worsening of the score in the placebo group. They also noted significantly reduced reports of oral and genital ulcers, pseudofolliculitis and erythema nodosum in the colchicine group. In contrast to the previous study, this study did not find a difference between results for male and female patients. ${ }^{22}$ 


\section{Epidermolysis bullosa acquisita}

Epidermolysis bullosa acquisita (EBA) is a rare, mucocutaneous blistering disease with onset in adults that is characterized by autoantibodies against collagen VII. Subepidermal blisters occur after mild trauma and heal with significant scarring. The efficacy of colchicine in treating this disease was first reported in 1989. In a retrospective study of 30 patients with EBA, colchicine was considered first-line therapy due to its low side effect profile, and a dose of $1.2 \mathrm{mg}$ per day was used. Patients additionally received dapsone and oral prednisone, and on this regimen mean time to remission was 9 months. ${ }^{23}$ Since then, there have been several case reports describing efficacy of monotherapy with colchicine for EBA. The suggested mechanism of action of colchicine in this disease is through inhibition of antibody secretion. ${ }^{24}$ In support of this theory, serum anti-type VII collagen antibody level titer decreased with colchicine treatment. Clinically, there was improvement in mucosal erosions, esophageal stenosis, dysphagia symptoms and cutaneous erosions. Incidentally, the hemoglobin A1c of one patient with diabetes mellitus type 2 was found to improve on colchicine therapy without change in diabetic management. ${ }^{24}$

\section{Leukocytoclastic vasculitis}

Leukocytoclastic vasculitis (LCV) is a common small vessel vasculitis that is characterized by palpable purpura and petechiae. Its etiology is diverse with both primary causes such as Henoch-Schonlein purpura and urticarial vasculitis, as well as secondary causes such as drug, infections and malignancies. Despite efficacy for colchine reported in multiple case reports, a prospective, randomized controlled trial of 41 patients showed no significant effect with colchicine $0.5 \mathrm{mg}$ daily versus topical emollients alone. Importantly, three patients in the trial did have complete response and had recurrence of disease after cessation of colchicine. ${ }^{25}$

\section{Sweet's syndrome}

Sweet's syndrome is a neutrophilic dermatosis first described in 1964 by Robert Douglas Sweet and characterized by an acute febrile illness with development of multiple tender, erythematous and edematous plaques. The etiology is not clear, but it is thought to be due to a hypersensitivity reaction to an underlying disease. In a retrospective study of 90 patients, colchicine was the predominant treatment with $48.9 \%$ of the cohort receiving it. A dose of 1-2 mg per day was used with regression of lesions in 1-14 days in 30 patients $(68.2 \%)$ receiving the drug. Of the 13 patients that did not respond to colchicine initially, there was improvement following the addition of prednisone. ${ }^{26}$

\section{Chronic urticaria}

Chronic urticaria is defined as urticarial lesions occurring at least twice a week without treatment for 6 weeks or more. A retrospective trial of 36 patients with chronic urticaria treated with colchicine for a mean duration of 7 months found that $56 \%$ of patients had a partial to complete response. Of the 15 patients with complete response, 9 patients remained in remission. ${ }^{27}$ 


\section{Recurrent apthous stomatitis}

Recurrent apthous stomatitis presents as painful ulcerative or erosive lesions of the oral mucosa, and it may be idiopathic or secondary to an underlying immune disorder such as Behçet's disease. Fontes et al performed a retrospective trial of 54 immunocompetent patients with severe apthous stomatitis, including those with Behçet's and those with idiopathic disease. Patients were treated with colchicine 1 to $1.5 \mathrm{mg} /$ day for a minimum of 3 months. After 3 months, 12 patients were disease free, 22 patients had at least 50\% decrease in frequency and duration of lesions, and 20 patients had no improvement or did not tolerate treatment. At follow-up of 72 months, 4 patients had no recurrence of disease. ${ }^{28}$ Similar findings were reported in a double-blind randomized trial of 34 patients randomized to 0.5 $\mathrm{mg}$ /day of colchicine versus $5 \mathrm{mg} /$ day of prednisolone for recurrent apthous stomatitis. Patients were treated for 3 months and both treatment groups had significant improvement in duration, symptoms, recurrence of lesions, and size of lesions. No significance difference in efficacy was found between either treatment group; however, patients treated with colchicine did report more adverse events, primarily gastrointestinal symptoms. ${ }^{29}$

\section{Actinic keratosis}

Actinic keratoses are common pre-malignant lesions with an approximately $10 \%$ risk of transforming into cutaneous squamous cell carcinoma over 10 years if left untreated. Recently, a double-blind randomized trial was performed of 70 actinic keratoses treated with $1 \%$ topical colchicine gel versus 3\% diclofenac gel twice a day for 3 weeks. In both treatment groups, there was a significant reduction in size of lesions after treatment. There was no difference in size of lesions at 30,60, and 120 days after treatment. Notably, colchicine gel was better tolerated than diclofenac gel, as over $20 \%$ of patients in the latter group reported erythema versus no patients in the colchicine group. ${ }^{30} \mathrm{~A}$ randomized trial of 16 patients with actinic keratoses treated with $0.5 \%$ versus $1 \%$ colchicine cream twice a day for 10 days found both concentrations to be efficacious in reduction in size and number of actinic keratoses, with resolution in 6 of 8 patients treated with $1 \%$ colchicine and 7 of 8 patients treated with $0.5 \%$ colchicine. No significant difference in efficacy was found between concentrations. ${ }^{31}$ A randomized double-blind trial of 20 patients treated with $1 \%$ colchicine gel versus placebo reported similar results with resolution of actinic keratoses in 7 of 10 patients treated with $1 \%$ colchicine gel. Burning and itching at day 2 or 3 of application was the only reported adverse effect with treatment. ${ }^{32}$

\section{Uses in Other, Non-Rheumatologic or Dermatologic Diseases}

One study published in 2015 sought to explore the relationship between colchicine use and the incidence of cancer. This study examined rates of malignancy in 24,000 male gout patients in Taiwan, comparing cancer incidence in "ever-users" and "never-users" of colchicine. The results demonstrated significantly lower incidence of all cause cancers after adjustment for age in the colchicine ever-users when compared with the never-users; findings were especially significant for prostate and colorectal cancers. ${ }^{33}$ According to ongoing oncologic investigations, colchicine appears to be one of the promising candidates on the horizon for combination chemoprevention agents or hybrid chemotherapy. ${ }^{34}$ 
Recent cohort studies have also examined the effects of colchicine on myocardial infarction (MI) and other cardiovascular events. Crittenden et al first assessed the relationship between MI and colchicine in gout patients, finding a significantly decreased prevalence of MI in the colchicine treated group as opposed to the non-colchicine group (1.2\% vs $2.6 \%$ ), with a trend towards decreased all-cause mortality. ${ }^{35} \mathrm{~A}$ more recent study assessing the rate of cardiovascular events in patients with gout found colchicine users to have a $49 \%$ lower risk of primary cardiovascular events that non colchicine users, and a $73 \%$ reduction in all-cause mortality. 36,37

Numerous controlled clinical trials support the safety and efficacy of a daily dose of colchicine for the treatment and prevention of acute pericarditis due to multiple causes. The 2004 European Society of Cardiology recommended colchicine for this purpose, based on small, non-randomized trials. ${ }^{2}$ Since then, multiple randomized controlled trials have supported this recommendation, including the CORE trial (COLchicine for REcurrent pericarditis), which found a $51 \%$ reduction in the rate of recurrent pericarditis in patients treated with colchicine for 18 months compared with $24 \%$ in the placebo group $(\mathrm{p}=0.02)$ as well as the Colchicine for Recurrent Pericarditis (CORP) study and the recently published CORP-2 trial, which reported a significant reduction in the rate of subsequent recurrences of pericarditis in patients with two or more recurrences. $38,39,40$

\section{Summary and Conclusion}

The list of therapeutic and prophylactic applications for colchicine in multiple fields of medicine is lengthening, as our appreciation of the anti-inflammatory properties of this natural drug expand and as our understanding of the many mechanisms affected by colchicine's action deepens (figure 4). A number of dermatologic diseases have already been found to respond to colchicine, and more thorough studies will likely reveal new uses for this ancient drug.

\section{Acknowledgments}

Authors thank Dr Vladimir Spiegelman, University of Wisconsin School of Medicine and Public Health for providing the UW-BCC1 cells. Authors thank Dr Christian Combs, National Heart Lung and Blood Institute Light Microscopy Facility for assistance imaging the UW-BCC1 cells.

This work was supported in part by the Intramural Research Program of the Eunice Kennedy Shriver National Institute of Child Health and Human Development, NIH. No other funding sources supported this work.

\section{References}

1. Roubille F, Kritikou E, Busseuil D, et al. Colchicine: an old wine in a new bottle? Antiinflamm Antiallergy Agents Med Chem. 2013; 12:14-23. [PubMed: 23286287]

2. Slobodnick A, Shah B, Pillinger MH, et al. Colchicine: old and new. Am J Med. 2015; 128:461-70. [PubMed: 25554368]

3. Komlodi-Pasztor E, Sackett DL, Fojo AT. Inhibitors targeting mitosis: tales of how great drugs against a promising target were brought down by a flawed rationale. Clin Cancer Res. 2012; 18:5163. [PubMed: 22215906]

4. Dalbeth N, Lauterio TJ, Wolfe HR. Mechanism of action of colchicine in the treatment of gout. Clin Ther. 2014; 36:1465-79. [PubMed: 25151572] 
5. Cronstein BN, Molad Y, Reibman J, et al. Colchicine alters the quantitative and qualitative display of selectins on endothelial cells and neutrophils. J Clin Invest. 1995; 96:994-1002. [PubMed: 7543498]

6. Asako H, Kubes P, Baethge BA, et al. Colchicine and methotrexate reduce leukocyte adherence and emigration in rat mesenteric venules. Inflammation. 1992; 16:45-56. [PubMed: 1312060]

7. Chia EW, Grainger R, Harper JL. Colchicine suppresses neutrophil superoxide production in a murine model of gouty arthritis: a rationale for use of low-dose colchicine. Br J Pharmacol. 2008; 153:1288-95. [PubMed: 18264123]

8. Marques-da-Silva C, Chaves MM, Castro NG, et al. Colchicine inhibits cationic dye uptake induced by ATP in P2X2 and P2X7 receptor-expressing cells: implications for its therapeutic action. $\mathrm{Br} \mathrm{J}$ Pharmacol. 2011; 163:912-26. [PubMed: 21306580]

9. Ahern MJ, Reid C, Gordon TP, et al. Does colchicine work? The results of the first controlled study in acute gout. Aust N Z J Med. 1987; 17:301-4. [PubMed: 3314832]

10. Terkeltaub RA, Furst DE, Bennett K, et al. High versus low dosing of oral colchicine for early acute gout flare: Twenty-four-hour outcome of the first multicenter, randomized, double-blind, placebo-controlled, parallel-group, dose-comparison colchicine study. Arthritis Rheum. 2010; 62:1060-8. [PubMed: 20131255]

11. Borstad GC, Bryant LR, Abel MP, et al. Colchicine for prophylaxis of acute flares when initiating allopurinol for chronic gouty arthritis. J Rheumatol. 2004; 31:2429-32. [PubMed: 15570646]

12. Wortmann RL, Macdonald PA, Hunt B, et al. Effect of prophylaxis on gout flares after the initiation of urate-lowering therapy: analysis of data from three phase III trials. Clin Ther. 2010; 32:2386-97. [PubMed: 21353107]

13. Zhang W, Doherty M, Pascual E, et al. EULAR recommendations for calcium pyrophosphate deposition. Part II: management. Ann Rheum Dis. 2011; 70:571-5. [PubMed: 21257614]

14. Dinarello CA, Wolff SM, Goldfinger SE, et al. Colchicine therapy for familial mediterranean fever. A double-blind trial. N Engl J Med. 1974; 291:934-7. [PubMed: 4606353]

15. Ben-Chetrit E, Levy M. Colchicine prophylaxis in familial Mediterranean fever: reappraisal after 15 years. Semin Arthritis Rheum. 1991; 20:241-6. [PubMed: 2042056]

16. Livneh A, Zemer D, Langevitz P, et al. Colchicine in the treatment of AA and AL amyloidosis. Semin Arthritis Rheum. 1993; 23:206-14. [PubMed: 8122124]

17. Zemer D, Pras M, Sohar E, et al. Colchicine in the prevention and treatment of the amyloidosis of familial Mediterranean fever. N Engl J Med. 1986; 314:1001-5. [PubMed: 3515182]

18. Kyle RA, Gertz MA, Greipp PR, et al. A trial of three regimens for primary amyloidosis: colchicine alone, melphalan and prednisone, and melphalan, prednisone, and colchicine. N Engl J Med. 1997; 336:1202-7. [PubMed: 9110907]

19. Cocco G, Chu DC, Pandolfi S. Colchicine in clinical medicine. A guide for internists. Eur J Intern Med. 2010; 21:503-8. [PubMed: 21111934]

20. Matsumura N, Mizushima Y. Leucocyte movement and colchicine treatment in Behcet's disease. Lancet. 1975; 2:813.

21. Yurdakul S, Mat C, Tüzün Y, et al. A double-blind trial of colchicine in Behçet's syndrome. Arthritis Rheum. 2001; 44:2686-92. [PubMed: 11710724]

22. Davatchi F, Sadeghi Abdollahi B, Tehrani Banihashemi A, et al. Colchicine versus placebo in Behçet's disease: randomized, double-blind, controlled crossover trial. Mod Rheumatol. 2009; 19:542-9. [PubMed: 19597921]

23. Kim JH, Kim YH, Kim SC. Epidermolysis bullosa acquisita: a retrospective clinical analysis of 30 cases. Acta Derm Venereol. 2011; 91:307-12. [PubMed: 21394418]

24. Adachi A, Komine M, Suzuki M, et al. Oral colchicine monotherapy for epidermolysis bullosa acquisita: Mechanism of action and efficacy. J Dermatol. 2016

25. Sais G, Vidaller A, Jucglà A, et al. Colchicine in the treatment of cutaneous leukocytoclastic vasculitis. Results of a prospective, randomized controlled trial. Arch Dermatol. 1995; 131:1399402. [PubMed: 7492128]

26. Amouri M, Masmoudi A, Ammar M, et al. Sweet's syndrome: a retrospective study of 90 cases from a tertiary care center. Int J Dermatol. 2016; 55:1033-9. [PubMed: 26967709] 
27. Pho LN, Eliason MJ, Regruto M, et al. Treatment of chronic urticaria with colchicine. J Drugs Dermatol. 2011; 10:1423-8. [PubMed: 22134566]

28. Fontes V, Machet L, Huttenberger B, et al. Recurrent aphthous stomatitis: treatment with colchicine. An open trial of 54 cases. Ann Dermatol Venereol. 2002; 129:1365-9. [PubMed: 12536172]

29. Pakfetrat A, Mansourian A, Momen-Heravi F, et al. Comparison of colchicine versus prednisolone in recurrent aphthous stomatitis: A double-blind randomized clinical trial. Clin Invest Med. 2010; 33:E189-95. [PubMed: 20519098]

30. Faghihi G, Elahipoor A, Iraji F, et al. Topical Colchicine Gel versus Diclofenac Sodium Gel for the Treatment of Actinic Keratoses: A Randomized, Double-Blind Study. Adv Med. 2016; 2016:5918393. [PubMed: 27689135]

31. Akar A, Bülent Taştan H, Erbil H, et al. Efficacy and safety assessment of $0.5 \%$ and $1 \%$ colchicine cream in the treatment of actinic keratoses. J Dermatolog Treat. 2001; 12:199-203. [PubMed: 12241628]

32. Grimaître M, Etienne A, Fathi M, et al. Topical colchicine therapy for actinic keratoses. Dermatology. 2000; 200:346-8. [PubMed: 10894974]

33. Kuo MC, Chang SJ, Hsieh MC. Colchicine Significantly Reduces Incident Cancer in Gout Male Patients: A 12-Year Cohort Study. Medicine (Baltimore). 2015; 94:e1570. [PubMed: 26683907]

34. Punganuru SR, Madala HR, Srivenugopal KS. Colchicine-Based Hybrid Anticancer Drugs to Combat Tumor Heterogeneity. Medicinal chemistry. 2016; 2016

35. Crittenden DB, Lehmann RA, Schneck L, et al. Colchicine use is associated with decreased prevalence of myocardial infarction in patients with gout. J Rheumatol. 2012; 39:1458-64. [PubMed: 22660810]

36. Solomon DH, Liu CC, Kuo IH, et al. Effects of colchicine on risk of cardiovascular events and mortality among patients with gout: a cohort study using electronic medical records linked with Medicare claims. Ann Rheum Dis. 2016; 75:1674-9. [PubMed: 26582823]

37. Solomon DH, Kim SC. Response to: 'Effects of colchicine on risk of cardiovascular events among patients with gout: as evidence accrues, is it time for a randomized trial?' by Giannopoulos and Deftereos. Ann Rheum Dis. 2016; 75:e29. [PubMed: 26929220]

38. Imazio M, Bobbio M, Cecchi E, et al. Colchicine as first-choice therapy for recurrent pericarditis: results of the CORE (COlchicine for REcurrent pericarditis) trial. Arch Intern Med. 2005; 165:1987-91. [PubMed: 16186468]

39. Imazio M, Brucato A, Cemin R, et al. Colchicine for recurrent pericarditis (CORP): a randomized trial. Ann Intern Med. 2011; 155:409-14. [PubMed: 21873705]

40. Imazio M, Belli R, Brucato A, et al. Efficacy and safety of colchicine for treatment of multiple recurrences of pericarditis (CORP-2): a multicentre, double-blind, placebo-controlled, randomised trial. Lancet. 2014; 383:2232-7. [PubMed: 24694983]

41. Cunningham BB, Kirchmann TT, Woodley D. Colchicine for epidermolysis bullosa acquisita. J Am Acad Dermatol. 1996; 34:781-4. [PubMed: 8632074]

42. Cozzani E, Basso D, Cimmino MA, et al. Generalized annular granuloma associated with crowned dens syndrome, which resolved with colchicine treatment. Clin Exp Dermatol. 2016; 41:640-2. [PubMed: 27335228]

43. Allali S, Fraitag S, Terrier B, et al. Efficacy of colchicine in a child with relapsing bullous HenochSchönlein purpura. Eur J Pediatr. 2016; 175:147-9. [PubMed: 26195178]

44. van der Zee HH, Prens EP. The anti-inflammatory drug colchicine lacks efficacy in hidradenitis suppurativa. Dermatology. 2011; 223:169-73. [PubMed: 21997700]

45. Scheer HS, Kamarashev J, Weibel L. Successful treatment of recurrent idiopathic plantar eccrine hidradenitis with colchicine. Arch Dermatol. 2012; 148:1357-9. [PubMed: 23247477]

46. Hodak E, Lapidoth M, David M. Effect of colchicine in the subcorneal pustular dermatosis type of IgA pemphigus. J Am Acad Dermatol. 1999; 40:91-4. [PubMed: 9922018]

47. Benbenisty KM, Bowman PH, Davis LS. Localized linear IgA disease responding to colchicine. Int J Dermatol. 2002; 41:56-8. [PubMed: 11895519]

48. Belani H, Gensler L, Bajpai U, et al. Neutrophilic urticaria with systemic inflammation: a case series. JAMA Dermatol. 2013; 149:453-8. [PubMed: 23715523] 
49. Wee E, Kelly RI. Treatment of nodular vasculitis with colchicine. Australas J Dermatol. 2016

50. Pandhi R, Jain R, Radotra BD, et al. Purpura annularis telangiectoides with vasculitic ulcers treated with colchicine. Int J Dermatol. 2002; 41:388-9. [PubMed: 12121548]

51. Parren LJ, Nellen RG, van Marion AM, et al. Penile pyoderma gangrenosum: successful treatment with colchicine. Int J Dermatol. 2008; 47(Suppl 1):7-9. [PubMed: 18986476]

52. Kontochristopoulos GJ, Stavropoulos PG, Gregoriou S, et al. Treatment of Pyoderma gangrenosum with low-dose colchicine. Dermatology. 2004; 209:233-6. [PubMed: 15459540]

53. Askari AD. Colchicine for treatment of relapsing polychondritis. J Am Acad Dermatol. 1984; 10:507-10. [PubMed: 6725661]

54. Mark KA, Franks AG. Colchicine and indomethacin for the treatment of relapsing polychondritis. J Am Acad Dermatol. 2002; 46:S22-4. [PubMed: 11807462]

55. Yüksek J, Sezer E, Köseoğlu D, et al. Scleredema treated with broad-band ultraviolet A phototherapy plus colchicine. Photodermatol Photoimmunol Photomed. 2010; 26:257-60. [PubMed: 21175853]

56. Kokpol C, Rajatanavin N, Rattanakemakorn P. Successful Treatment of Scleredema Diabeticorum by Combining Local PUVA and Colchicine: A Case Report. Case Rep Dermatol. 2012; 4:265-8. [PubMed: 23275772]

57. Loricera J, Calvo-Río V, Mata C, et al. Urticarial vasculitis in northern Spain: clinical study of 21 cases. Medicine (Baltimore). 2014; 93:53-60. [PubMed: 24378743]

58. Noubissi FK, Kim T, Kawahara TN, Aughenbaugh WD, Berg E, Longley BJ, Athar M, Spiegelman VS. Role of CRD-BP in the growth of human basal cell carcinoma cells. J Invest Dermatol. 2014 Jun; 134(6):1718-24. [PubMed: 24468749] 


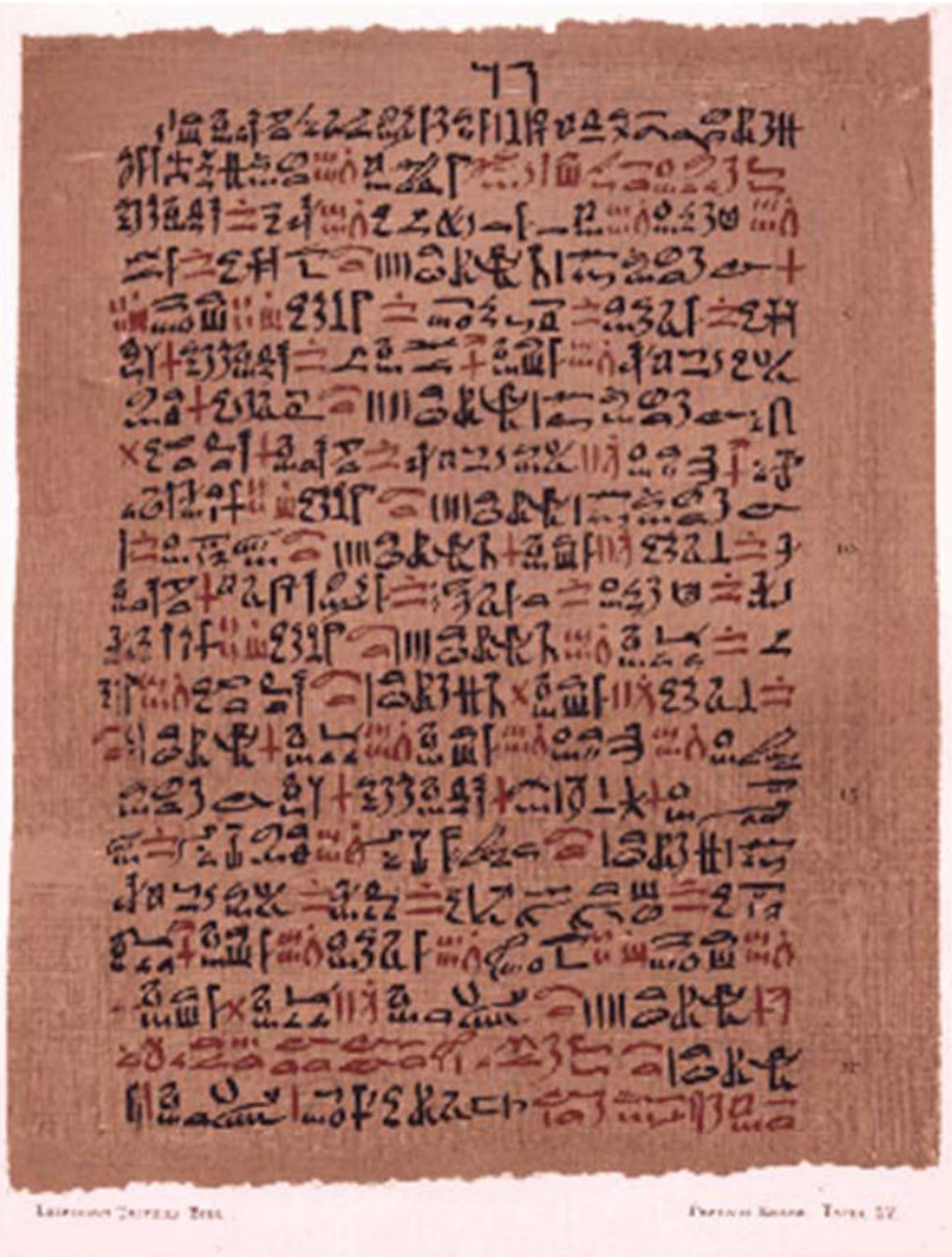

Figure 1.

The Ebers Papyrus is one of the most important medical documents from ancient Egypt. It was produced ca $1550 \mathrm{BCE}$, and is currently housed in the library of the University of Leipzid, Germany. Image is public domain from the National Library of Medicine NIH Archives. https://www.nlm.nih.gov/archive/20120918/hmd/breath/breath_exhibit/ MindBodySpirit/IIBa18.html 


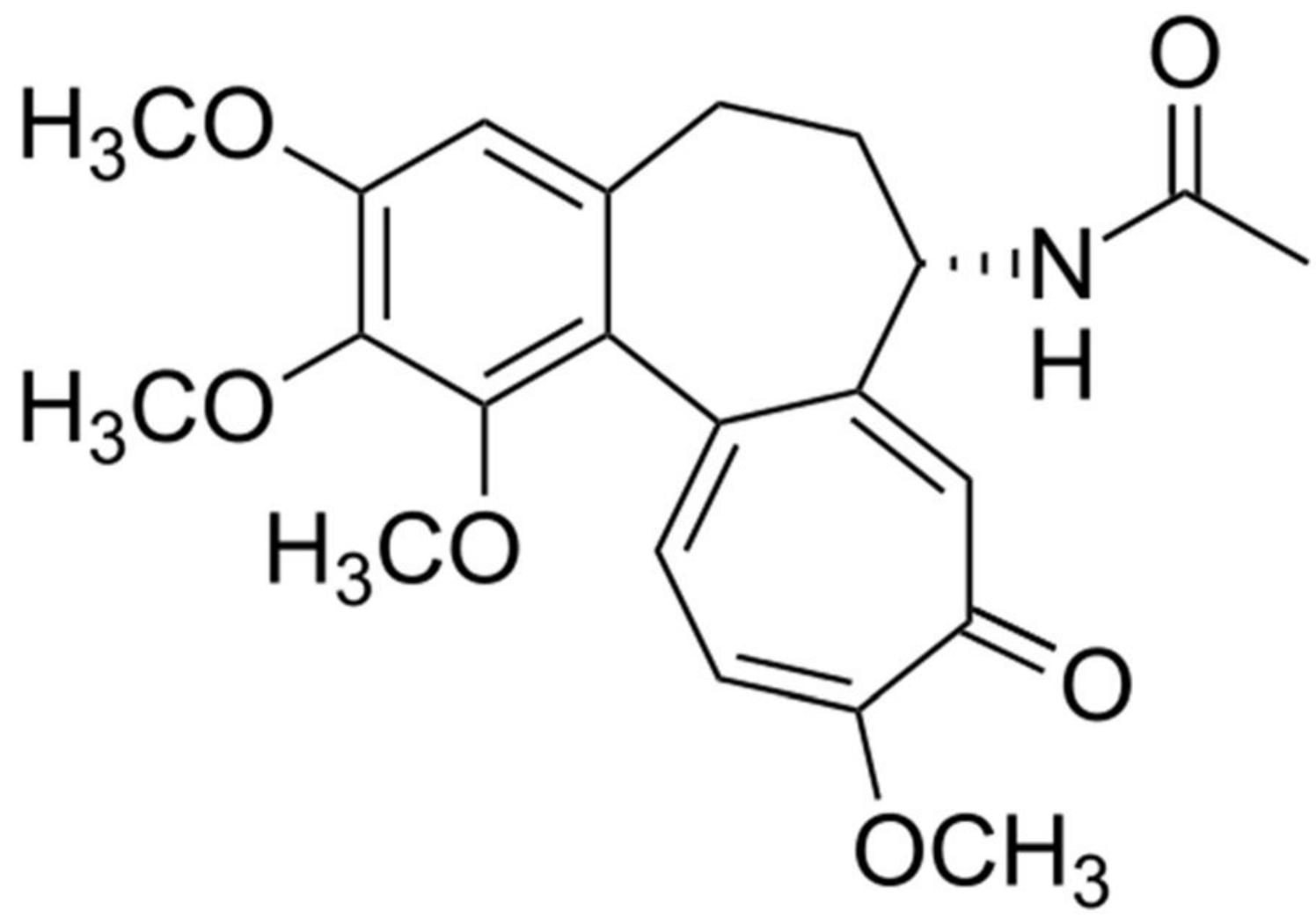

Figure 2.

The chemical structure of colchicine. 


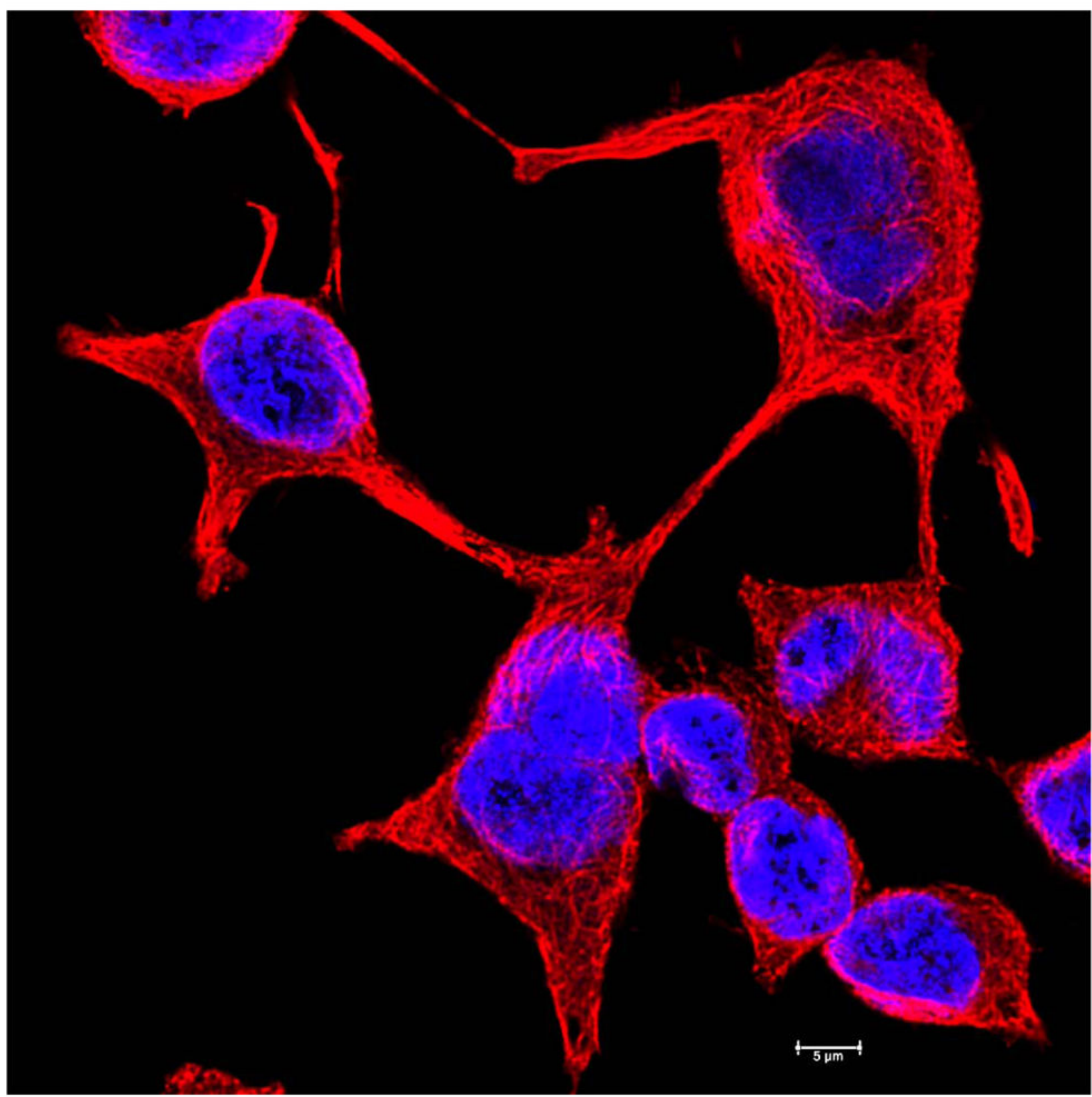

Figure 3.

Fluorescence microscopy images of basal cell carcinoma cell line showing the microtubule cytoskeleton and the nucleus. The cells are UW-BCC1 cells (58), grown on glass coverslips and imaged. Microtubules (red) were imaged by immunostaining with monoclonal antialpha tubulin antibody and the DNA in the nucleus (blue) was revealed by Hoechst stain. Scale bar is $20 \mu \mathrm{m}$. 


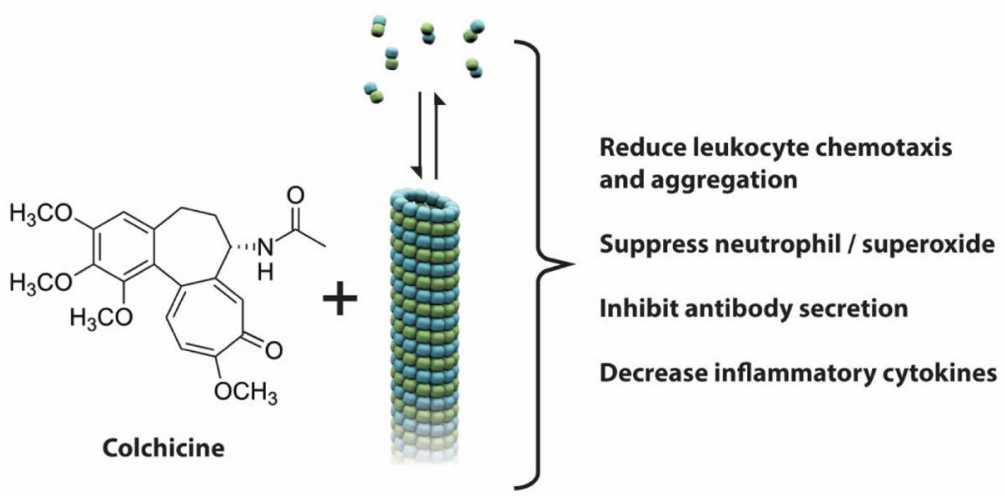

Figure 4.

Summary of colchicine's actions in clinical applications. Colchicine interacts with tubulin, altering the tubulin - microtubule balance. This change in the dynamics of the cellular microtubule arrays results leads to changes in cell motility / chemotaxis, as well as changes in secretion, as indicated in the figure. 


\section{Table 1}

\begin{tabular}{|lll|}
\hline Disease & Level of evidence & Reference \\
\hline Actinic keratosis & $1^{\wedge}$ & $30-32$ \\
\hline Behcet's disease & 1 & 22 \\
\hline Chronic urticaria & 2 & 27 \\
\hline Epidermolysis bullosa acquisita & $2 / 3$ & $23,24,41$ \\
\hline Granuloma annulare & 3 & 42 \\
\hline Henoch-Schonlein purpura & 3 & 43 \\
\hline Hidradenitis suppurative & $3 *$ & 44 \\
\hline Idiopathic plantar eccrine hidradentis & 3 & 45 \\
\hline Linear IgA & 3 & 46,47 \\
\hline Leukocytoclastic vasculitis & $3^{*}$ & 25 \\
\hline Neutrophilic urticaria & 3 & 48 \\
\hline Nodular vasculitis & 3 & 49 \\
\hline Purpura annularis telangiectoides & 3 & 50 \\
\hline Pyoderma gangrenosum & 3 & 51,52 \\
\hline Recurrent apthous stomatitis & $1 / 2$ & 28,29 \\
\hline Relapsing polychondritis & 3 & 53,54 \\
\hline Scleredema & 3 & 56 \\
\hline Sclerederma diabeticorum & 3 & 56 \\
\hline Sweet's syndrome & 2 & \\
\hline Urticarial vasculitis & 3 & \\
\hline & 3 & \\
\hline
\end{tabular}

* No significant effect observed or not efficacious

Topical colchicine was used

$1=$ Prospective controlled trial

$2=$ Retrospective trial or larger case series $(>20$ patients $)$

$3=$ Small series or individual reports 